\title{
Environmental protection when processing road-building materials
}

\author{
Gulchekhra Mirzaeva', Abdug'aniyev Nazirjon ${ }^{2}$ \\ ${ }^{1,2}$ Senior Lecturer Ferghana Polytechnic Institute \\ Republic of Uzbekistan, Ferghana \\ E-mail: yunusali1987@mail.ru1,yunusali1987@mail.ru
}

\begin{abstract}
This article presents the most acceptable ways of recycling waste road building materials, as well as the main measures to eliminate the negative impact on the environment of waste road building materials obtained in the process of construction, restoration and reconstruction of roads. These activities will solve a number of problems associated with the negative impact on the environment of construction waste.
\end{abstract}

Key words: Environment, ecology, road construction wast e, construction scrap. industry, recycling, asphalt, bitumen, environmental assessment, negative impact, quarry, road dismantling

\section{Introduction}

However, it should be borne in mind that at present, construction and road waste, which is generated during the process of road construction, reconstruction, major and current repair of roads, restoration and restoration works, has a negative impact on the environment. Due to the growth in the volume of reconstruction and repair of roads, construction and road waste is growing. At the moment, two methods are used for the disposal of waste of construction and road materials, storage and recycling. Picking is currently the only way of disposal. However, recycling, one of the disposal methods, has several advantages. ...

From an environmental point of view, modern methods of disposal of road construction waste are considered, which is one of the main problems in the field of improving the environmental situation. Due to intensive construction and reconstruction of roads, a large amount of road construction waste appears annually, which must be disposed of. The volume of road repairs is growing every year, and along with them the number of old pavements grows, it is even difficult to calculate how much construction waste is generated. [five].

Road construction waste is various particles of waste materials used in the process of road reconstruction. During the repair and reconstruction of roads, many different materials remain - bitumen, cement, fragments of tiles, concrete, remnants of reinforced concrete structures. The economic efficiency of reuse and recycling of construction waste allows 2-3 times to reduce the cost of the finished secondary product, can reduce the cost of road construction. [1] For example, crumbs of reinforced concrete are used for backfilling roads and added to chamotte, and crushed concrete and reinforced concrete can be used as a large aggregate in the preparation of foundation blocks from concrete. Recycling of construction waste, ensures the reuse of used materials of old asphalt, reinforced concrete scrap, which allows significant savings: the material does not need to be removed from the construction site, spending money and time on loading, transporting and unloading, no need to pay for landfill space. Where roads are being repaired, there will always be construction of new ones, which means that concrete, asphalt, crushed stone, bitumen will be needed. Recycling of raw materials allows for green and economical production. When producing concrete, it is more profitable and cheaper to add crushed concrete to it. [2] Thorough processing of waste materials, down to the last stone and then their recycling, can significantly save on consumables, reduce production costs, improve the environmental situation, and get good economic benefits. In addition to concrete, the main construction waste that remains after road repair is reinforced concrete, that is, their use is especially important to use for laying temporary roads. Recycling road construction waste can be an excellent material for filling unnecessary voids or pits. Construction waste such as asphalt is used in the construction of road pavement, having been pretreated thermally at a high temperature, which allows the resinous substance to be melted. In case of loss of viscosity or other qualities, special strengthening and concreting substances are added to the asphalt.

\section{Main part}

The ecology of the environment is influenced by the process itself accompanying the extraction of raw materials for its manufacture of a product before its destruction, or for its reuse in the manufacture of new materials, which also allows solving environmental problems - to reduce the amount of waste and ensure resource conservation. Environmental safety is assessed not only by direct (obvious) negative impact, such as the impact of harmful substances, waste generation, but also the impact on human health, deterioration of the quality of the environment. [3] 
The degree of interaction of road-building waste obtained during the repair and construction of highways with the environment is based on a comparative analysis, which gives a relative assessment of the load on humans and the environment.

Typically, an environmental impact assessment of waste consists of the following main parts:

- development and establishment of the means of exploitation of the waste product;

- assessment of their impact on the environment.

\section{Analyses}

Environmental assessment of road construction waste on the environment should be carried out on the following components: atmosphere, hydrosphere, soil, and biotic components (including humans). In environmental assessment, first of all, it is necessary to take into account the negative impacts leading to the aggravation of environmental problems, such as the greenhouse effect, soil pollution, resource depletion, etc.

The negative effects include:

- depletion of resources;

- air pollution;

- pollution of the water eco-system

- destruction of the soil cover;

- landscape change;

- waste generation;

- violation of natural balance in the ecosystem;

- destruction of vegetation; and etc.

The environmental impact assessment includes an analysis of the following stages:

- extraction of raw materials;

- manufacturing of materials and products;

- road construction stage (material application);

-operation (the need to maintain its quality of repair, restoration, reconstruction);

- reuse (when changing material, dismantling):

- destruction (waste, after repair and reconstruction of roads.)

Almost all raw materials for repairs, road materials are mined by open cut mining, which leads to significant disturbance of land plots. Quarries and waste rock dumps remain at the site of the deposit. Some quarries are gradually filled with water or landfills. Disturbed lands require restoration of soil and vegetation cover; sand dumps and quarries are the fastest growing. Quarries are overgrown more slowly and mainly with weeds. The restoration of vegetation in dry lime pits is even worse. It is recommended to remove the fertile layer from the surface of the earth and store it before starting the development of a quarry. After mining, the surface of the quarry is usually filled up, leveled, and a preserved fertile soil layer is applied on top.

When processing road construction waste, it is imperative to analyze what negative consequences for the environment are to be faced. Enterprises producing and processing road building materials pose a significant environmental hazard. At the production stage, there are a number of serious problems: harmful emissions into soil, water, air, waste. The environmental load depends on the number of processing stages, for example, bitumen includes many technological processes. In the production of organic binders, synthetic polymeric materials, harmful substances and gases are released. [4]

The main sources of air pollution are considered to be production, bitumen, asphalt, chemical production, enterprises for the production of insulation materials, concrete plants, etc. Waste from these enterprises has a negative impact on soils, water bodies and the environment.

The state of the environment is influenced by waste from cement plants. From the smallest cement dust deposited in the vicinity of these enterprises, vegetation dies, the soil ecosystem is destroyed, people and animals get sick with lung diseases

\section{Research and discussions}

In the production of road building materials, it is necessary to take into account the possibility of its reuse without significant additional processing (for example, asphalt, concrete, reinforced concrete structures, etc.). For reuse, it is very important that the materials are well sorted and cleaned. If waste gets into the environment (landfills, etc.), then they will begin to decompose gradually in the natural environment, for tens of hundreds of years. [1]

It is possible to give an environmental assessment of the material at every stage - from the extraction of raw materials to the destruction of the material. emissions of solid, liquid and gaseous harmful substances into soil, water or air. are 
hazardous to the environment.

Typically, the impact of materials on the environment is assessed in terms of human "health". The negative impact of waste on human health is analyzed through the negative impact:

- extraction of raw materials (for example, dust causes all kinds of diseases: allergies, asthma, etc.);

- road construction and repair (influence of vapors, bitumen, high temperatures, etc.);

- operation (hazardous substances are released into the air of the premises);

- processing of waste near settlements (influence of vapors, dust, gases, high temperatures, etc.)

Modern industry produces hundreds of different types of road building materials. Waste naturally occurs at different stages of the technological process. Part of the waste is lost with wastewater, with waste gases, when grinding solid products, as a result of which the atmosphere, hydrosphere, and soil are polluted. For the storage of solid waste, special dumps and landfills are built, and open pits are used.

Typically, production spends, on average, $8-10 \%$ of the value of manufactured products for transportation, storage, concentration, neutralization, burial, and waste collection. Production waste can also become a powerful source of raw materials for industry. Consideration should always be given to the possibility of re-using road building materials, in particular the possibility of their recycling and reuse.

When comparing the different aspects of the environmental impact of road waste, it is important to consider whether the damage done to the ecosystem is being repaired. The environmental, technical and economic opportunities in the country where the material will be used also play an important role in the assessment. The common thing when evaluating and choosing a material is the need to always take into account the increase in the volume of work. This almost always leads to an increase in road waste. When choosing a material, you should consider what (and in what quantity) auxiliary materials and work will be required for its reuse. Waste road building materials affecting the ecology of the environment: dust, sand, gravel, asphalt, bitumen. [5]

The author made an attempt to substantiate the most acceptable ways of waste disposal during the reconstruction and repair of roads, and also developed measures to eliminate the thermal impact on the environment of waste of road building materials resulting from the construction, reconstruction and repair of roads.

The implementation of the measures proposed in this work allows us to solve a number of problems associated with the negative impact on the environment of waste of road building materials, in particular:

- elimination of construction waste and construction waste dumps;

- increasing the cleanliness of the air basin from pollution as a result of incineration of road construction waste and waste;

- the introduction of resource-saving technologies for the processing of road construction waste, allowing to save building materials: crushed stone, bitumen.

The volume of annually removed old asphalt concrete pavements in each city is tens of thousands of tons, and in general, about a million tons of dismantled asphalt concrete "runs up" for highways annually. Asphalt scrap, being in the status of a secondary resource, is an excellent repair and construction material. The advantages of asphalt scrap are the following qualities: [4]

- durability against mechanical static and dynamic loads;

- resistance to atmospheric moisture and chemically active substances;

- resistance to sudden temperature changes;

- the possibility of further crushing by crushing with a jackhammer;

- low cost.

Dismantling the old asphalt pavement results in the formation of pieces of asphalt concrete of various sizes called asphalt scrap. The main components of asphalt and asphalt concrete pavement - crushed stone, sand and bitumen residues remain in the composition of such waste-scrap.

The thickness of the removed layers is from 5 to $15 \mathrm{~cm}$.

The sizes of asphalt pieces are not standardized. However, in the practice of separating asphalt blocks, it is customary to divide into three conditional groups:

- small waste, the size of which does not exceed $20 \mathrm{~cm}$;

- average scrap with dimensions of elements 15-40 cm;

- large lumps of more than half a meter in size.

Asphalt concrete is the result of technological mixing of bitumen with inert materials - crushed stone, gravel and 
sand, which significantly increase the strength characteristics of the asphalt concrete mixture. In other words, asphalt concrete is a modified version of traditional road asphalt pavement.

Asphalt concrete coating (ABP) contains bitumen only 4.5-6.0\%, the rest is crushed stone, gravel and sand ..

Modern technologies for the regeneration and recycling of asphalt concrete pavements are the processing of an asphalt concrete pavement (ABP) worn out during operation with the addition of its technical indicators and physical and chemical characteristics to the required level. [6]

\section{Conclusion}

Asphalt is an organic binder of natural or artificial5 origin with a different content of bitumen in its composition (from $13 \%$ to 70 )

Regeneration of the dismantled $\mathrm{ABP}$ is aimed at restoring and improving the technical and operational characteristics of asphalt concrete material in order to reuse it for asphalt paving of highways or other road repair works.

After the expiration of the service life of the road surface, up to $90 \%$ of the useful mass of asphalt concrete material suitable for further use remains in its composition.

\section{References:}

1. Alekhin Yu.A., Lyusov A.N. "The economic efficiency of using secondary resources in the production of building materials." M., 1988, 275p

2. Gusev P.I. "Aggregates from destroyed concrete”. M., 1988, 96p

3. Barovskiy V.G. "Road transport safety". M., Higher School, 2007, 195 p.

4. Buslaev M.R "Environmental protection and transport", M., Mashinostroitel, 2007, 250 p.

5. G.S. Mirzaev. "Measures to improve the conditions and labor protection of drivers engaged in the transport of dangerous goods in the industrial complex of the Republic." Scientific and technical journal volume 21 No. 12017 $230 \mathrm{p}$

6. G.S. Mirzaeva. "Organization of traffic safety in winter in the mountain roads of the Fergana Valley." Scientific-technical journal volume 22 .№4 2018g154p 